\title{
Factors Associated with the Initiation of Biologic Disease-Modifying Antirheumatic Drugs in Texas Medicaid Patients with Rheumatoid Arthritis
}

\author{
Gilwan Kim, PharmD, MS; Jamie C. Barner, PhD; Karen Rascati, PhD; and Kristin Richards, PhD
}

\section{ABSTRACT}

BACKGROUND: Rheumatoid arthritis (RA) is a progressive autoimmune disorder of joints that is associated with high health care costs, yet guidance is lacking on how early to initiate biologic disease-modifying antirheumatic drugs (DMARDs), a class of medications that is the major cost driver in RA management. Few studies have examined the factors associated with the transition from nonbiologic DMARDs, the first-line therapy for RA, to biologic DMARDs in RA patients.

OBJECTIVE: To examine patient sociodemographics, medication use patterns, and clinical characteristics associated with initiation of biologic DMARDs.

METHODS: This was a retrospective study using the Texas Medicaid prescription and medical claims database from July 1, 2003-December 31, 2010. Adults (aged 18-63 years) with an RA diagnosis (ICD-9-CM code 714.xx), no nonbiologic DMARD or biologic DMARD use during the 6-month pre-index period, and a minimum of 2 prescription claims for the same nonbiologic DMARD during the post-index period were included in the study. The index date was defined as the date when the first nonbiologic DMARD claim was made. Predictors of initiation of biologic DMARDs were age, gender, race, adherence (proportion of days covered), persistence to nonbiologic DMARDs, comorbidity (Charlson Comorbidity Index [CCI]), pain medication use, glucocorticoid use, and rheumatologist visit. Logistic regression was used to examine the factors associated with the initiation of biologic DMARDs.

RESULTS: A total of 2,714 patients were included. After controlling for patient characteristics, logistic regression showed, that compared with methotrexate (MTX) users, sulfasalazine (SSZ) and hydroxychloroquine (HCQ) users were less likely to initiate biologic DMARDs by $69.0 \%$ $(\mathrm{OR}=0.310,95 \% \mathrm{Cl}=0.221-0.434, P<0.0001)$ and $79.9 \%(\mathrm{OR}=0.201,95 \%$ $\mathrm{Cl}=0.152-0.265, P<0.0001)$, respectively. Nonbiologic DMARD dual therapy users were $39.1 \%$ less likely to initiate biologic DMARDs compared with nonbiologic DMARD monotherapy users $(\mathrm{OR}=0.609,95 \% \mathrm{Cl}=0.463-0.803$, $P=0.0004)$. With each year increase in age, patients were $1.6 \%$ less likely to start biologic DMARDs (OR=0.984, $95 \% \mathrm{Cl}=0.975-0.993, P=0.0006)$. Compared with glucocorticoid users, glucocorticoid nonusers were $53.8 \%$ less likely to start on biologic DMARDs (OR $=0.462,95 \% \mathrm{Cl}=0.372-0.573$, $P<0.0001$ ). Patients with $\mathrm{CCl}$ scores of $\geq 3$ were approximately 1.6 times more likely to initiate biologic DMARDs than those with $\mathrm{CCl}$ scores of 1 (0R=1.618, 95\% $\mathrm{Cl}=1.228-2.132, P=0.0006)$.

CONCLUSIONS: Younger age, CCI scores $\geq 3$, glucocorticoid use, MTX users (vs. SSZ and HCQ users), and nonbiologic DMARD monotherapy users (vs. dual therapy users) were significantly associated with higher likelihood to initiate biologic DMARDs. Recognizing these potential factors that drive the initiation of biologic DMARDs in this patient population, health care providers and Texas Medicaid should take measures to achieve optimal therapy for RA patients through thorough RA medication evaluation, well-structured RA monitoring programs, and patient education.

J Manag Care Spec Pharm. 2015;21(5):401-07

Copyright $\odot 2015$, Academy of Managed Care Pharmacy. All rights reserved.

\section{What is already known about this subject}

Rheumatoid arthritis (RA), the second most common arthritis, is associated with low quality of life as well as significant economic burden on employers and society.

Current RA treatment guidelines recommend nonbiologic disease-modifying antirheumatic drugs (DMARDs) as first-line therapy. If targeted outcomes are not achieved with nonbiologic DMARD monotherapy, nonbiologic DMARD combination therapy is recommended before moving to advanced therapy, which may include an addition of or switch to a biologic DMARD agent. Among biologic DMARD initiators, the majority (86\%) previously received nonbiologic DMARDs, with increasing percentages of those with shorter disease duration and less disease severity at initiation of biologic DMARDs.

While no established guidelines exist regarding when to initiate biologic DMARDs, sociodemographic (age, income, ethnicity/ race, and insurance type) and clinical factors (disability, RA severity, and previous therapy with steroids or nonbiologic DMARDs) may be associated with the initiation of biologic DMARDs.

\section{What this study adds}

Younger age, Charlson Comorbidity Index scores $\geq 3$, glucocorticoid use, MTX users (vs. SSZ, HCQ users), and nonbiologic DMARD monotherapy users (vs. dual therapy users) are significant driving factors in transitioning from nonbiologic DMARDs to biologic DMARDs.

Health care providers may want to consider targeting patients who are more likely to initiate biologic DMARDs for patient education and thorough medication therapy evaluation-both of which can potentially reduce avoidable health care costs 
$\mathrm{R}$ heumatoid arthritis (RA) is a progressive autoimmune disorder that is characterized by chronic inflammation of multiple joints and is the second most common arthritis after osteoarthritis. ${ }^{1-4}$ RA patients may experience a wide range of symptoms from joint stiffness, pain, swelling, and chronic joint deformities to extra-articular (i.e., "outside of the joint") complications (e.g., rheumatoid nodules, vasculitis, pleural effusions, pulmonary fibrosis, pericarditis, and bone marrow suppression). ${ }^{5}$ RA affects approximately 1.3 million adults in the United States. ${ }^{6,7}$ The prevalence of RA is approximately $0.3 \%-1.0 \%$ among adults, and it is higher among older individuals (average age $\sim 67$ years), females, and those in developed countries. ${ }^{6,8} \mathrm{RA}$ patients have lower quality of life, since they often experience persistent pain as well as functional disability and psychological problems. ${ }^{9}$ Patients with established RA are known to have an average of 2 or more comorbidities, with a mortality rate 1.5-1.6 times higher than that of the general population. ${ }^{10,11}$ RA places an economic burden on employers and society. A recent study reported that U.S. employees with RA $(\mathrm{N}=2,705)$ had, on average, annual direct costs (medical and prescription) of $\$ 7,445$ (\$4,687 higher than those without RA, $P<0.0001)$ and indirect costs (sick leave, short- and long-term disability, and workers' compensation absences) of $\$ 1,262$ ( $\$ 525$ higher than those without RA, $P<0.05)$ per patient. Based on this study, the total annual economic burden of RA to employers was $\$ 5.8$ billion ( $\$ 5.2$ billion in direct costs and $\$ 579$ million in indirect costs) and 4.0 million incremental work loss days. ${ }^{12}$

In RA management, medications are fundamental to treatment and can be divided into 3 categories: (1) symptomatic drugs (e.g., nonsteroidal anti-inflammatory drugs, acetaminophen, and opioid analgesics), which help alleviate pain; (2) disease-modifying antirheumatic drugs (DMARDs), which are classified into nonbiologic and biologic and reduce inflammation and joint damage; and (3) glucocorticoids (GCs), which have anti-inflammatory and disease-modifying properties that help with symptom relief and mitigation of disease progression. Nonbiologic DMARDs, also known as conventional DMARDs, have been used to slow disease progression for decades. Examples of nonbiologic DMARDs include methotrexate (MTX), sulfasalazine (SSZ), leflunomide (LEF), and hydroxychloroquine (HCQ). ${ }^{13,14}$ Biologic DMARDs are relatively new agents that have a significant effect on disease activity, functional capacity, and structural damage. ${ }^{15,16}$ One significant difference between nonbiologic and biologic DMARDs is cost. Nonbiologic DMARD costs range from $\$ 30$ to $\$ 900$ monthly, whereas biologic DMARD costs range from $\$ 2,000$ to $\$ 5,000$ monthly. ${ }^{17}$ Current RA treatment guidelines agree that nonbiologic DMARDs should be the first-line therapy and should be initiated immediately upon diagnosis. ${ }^{13,16}$ MTX or LEF are usually the drugs of choice among nonbiologic DMARDs. MTX has been a preferred drug because of its effec- tiveness and relatively low side effect profile with long-term use. ${ }^{13,14}$ If targeted outcomes are not achieved with nonbiologic DMARD monotherapy, nonbiologic DMARD combination therapy is recommended before moving to advanced therapy, which may include an addition of, or switch to, a biologic DMARD agent. ${ }^{13,14}$

It is important to understand more about the initiation of biologic DMARDs because of their significant costs. The purpose of this study was to examine patient sociodemographics, medication use patterns, and clinical characteristics associated with initiation of biologic DMARDs.

\section{Methods}

\section{Study Design and Population}

This retrospective study used Texas Medicaid prescription and medical claims databases from July 1, 2003-December 31, 2010. The study was reviewed by The University of Texas at Austin Institutional Review Board.

Patients were included in the study if they met the following criteria: (a) aged 18-63 years at the index date; (b) continuously enrolled for at least 6 months before and 24 months after the index date; (c) diagnosed with RA (International Classification of Diseases, Ninth Revision, Clinical Modification [ICD-9-CM] code 714.xx) during the pre-index period; (d) no nonbiologic DMARD used during the pre-index period; (e) no biologic DMARD used during the pre-index period; (f) at least 2 of the same nonbiologic DMARDs used in the post-index period. The index date was defined as the date of the first nonbiologic DMARD claim. Dual therapy was defined as having 2 nonbiologic DMARDs filled with 2 overlapping periods of at least 15 days, with the first claim filled within 4 months of the index date. For both monotherapy and dual therapy, patients were treatment naive in the pre-index period. All patients were followed until biologic initiation or for 24 months, whichever came first.

Patients were excluded from the study if they were diagnosed with other types of arthritic or autoimmune disorders such as psoriasis (ICD-9-CM 696.0x), psoriatic arthritis (ICD-9-CM 696.1x or 696.8x), ankylosing spondylitis (ICD-9-CM 720.0x), ulcerative colitis (ICD-9-CM 556.9), or Crohn's disease (ICD9-CM 555.0x, 555.1x, 555.2x, 555.9x, 565.1x, or 569.81) during the entire study period because biologic DMARDs are indicated for treatment with these disorders. In addition, patients with comorbid disorders such as leukemia (ICD-9-CM 208.x); nonHodgkin's lymphoma (ICD-9-CM 202.8x); head, neck, lung, and breast cancers (ICD-9-CM 171.0, 162.9, 174.9); osteosarcoma (ICD-9-CM 170.9); mycosis fungoides (ICD-9-CM 202.1); gestational trophoblastic neoplasm (ICD-9-CM 181); lupus erythematosus (ICD-9-CM 710.0); malaria (ICD-9-CM 084.6); collagen disease (ICD-9-CM 710.9); exacerbation of multiple sclerosis (ICD-9-CM 340); idiopathic thrombocytopenic purpura (ICD-9-CM 287.3); neoplastic disease (ICD- 


\section{FIGURE 1 Patient Attrition}

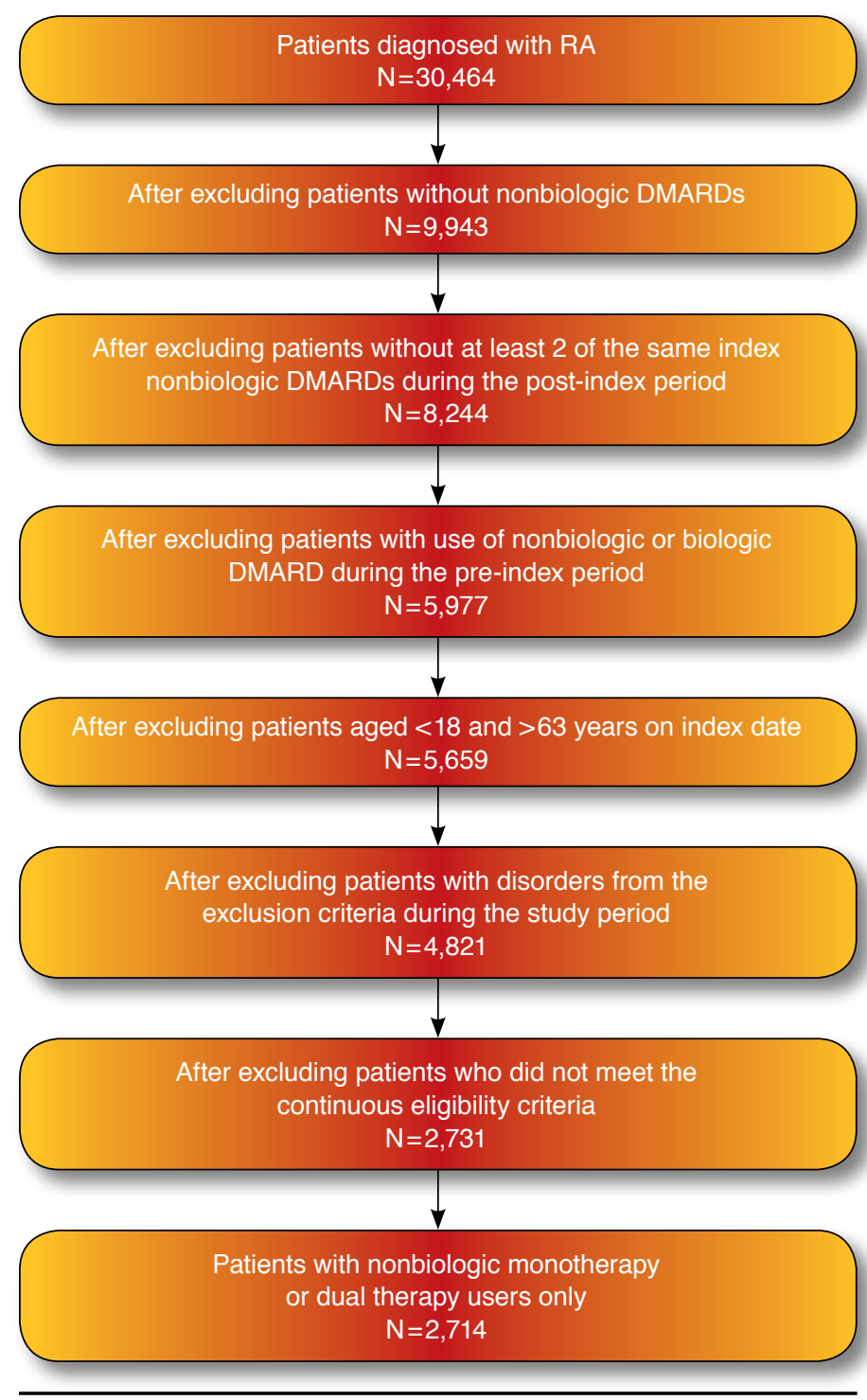

DMARD = disease-modifying antirheumatic drug; $R A=$ rheumatoid arthritis.

9-CM 239.9); nephritis disease/syndrome (ICD-9-CM 581); polymyositis (ICD-9-CM 710.4); renal transplant rejection (ICD-9-CM 996.81); heart transplant (ICD-9-CM V42.1); trichinosis (ICD-9-CM 124); and tuberculosis meningitis (ICD-9-CM 013.0) during the study period were excluded because these disorders are also treated with nonbiologic DMARDs or GCs. ${ }^{17}$

\section{Study Variables}

The likelihood of initiating biologic DMARDs was compared by nonbiologic DMARD type (MTX, SSZ, HCQ, and LEF) and therapy (mono vs. dual therapy). Covariates included age, gen-

der, race, adherence and persistence to nonbiologic DMARDs, comorbidity, pain medication use, GC use, and rheumatologist visit. Adherence was measured using the proportions of days covered (PDC), which was defined as the proportion of the number of days when drugs were available over the number of days in the study period. Because there were no data on the days supply for MTX injectables in the database, dosing intervals were assumed, depending on the dose in data analysis. Persistence was defined as the number of days in which a nonbiologic DMARD was continuously used during the post-index period without a gap. A grace gap period of last days supply plus 60 days was applied. Comorbidity was examined using Charlson Comorbidity Index (CCI). Pain medication use, GC use, and rheumatologist visit were dichotomously measured as "yes" or "no."

\section{Statistical Analysis}

Descriptive statistics were used to assess patient baseline characteristics. In comparing the demographic and clinical characteristics between the biologic DMARD starter group and the nonstarter group, unadjusted bivariate analysis was performed. Logistic regression analysis was used to examine the likelihood of initiation of biologic DMARDs by nonbiologic DMARD type and therapy, while controlling for patient sociodemographics, medication utilization patterns, and clinical factors.

\section{Results}

\section{Baseline Characteristics}

Of the total sample of 30,464 patients, $8.9 \%$ (2,714 patients) were included in the study (Figure 1). Table 1 shows that the majority of patients were aged 45-63 years $(68.8 \%)$ with a mean ( \pm standard deviation $[S D])$ age of $48.1( \pm 10.4)$ years. The patients were predominantly female (89.1\%) and Hispanic (55.3\%). With respect to nonbiologic DMARD type, $44.8 \%$ of patients were prescribed MTX, followed by HCQ (25.1\%). Approximately a tenth of the patients (13.6\%) were dual therapy users. The majority of patients (86.4\%) were monotherapy nonbiologic DMARD users. Mean PDC adherence for nonbiologic DMARDs was $30.6 \%( \pm 25.2 \%)$. The vast majority $(89.9 \%)$ of patients were nonadherent (PDC $<70 \%$ ), and their mean persistence was $190.2( \pm 201.4)$ days. Regarding other medication use, most patients shifted from GC nonusers $(69.8 \%)$ in the pre-index period to GC users (64.9\%) in the post-index period. Over $90 \%$ of the sample (92.4\%) were on pain medications in the post-index period. The majority of patients had either a CCI score of 1 (58.9\%) or $2(28.9 \%)$. Finally, $73.9 \%$ of patients were prescribed a nonbiologic DMARD by a nonrheumatologist.

When the baseline characteristics were compared on biologic DMARD initiation status (Table 2), the unadjusted bivariate analyses showed that biologic DMARD nonstarters were significantly (but not practically) older than starters (48.3 $[ \pm 10.3])$ vs. $47.3[ \pm 10.8]$ years, $P=0.03)$, and there were 
Factors Associated with the Initiation of Biologic Disease-Modifying

Antirheumatic Drugs in Texas Medicaid Patients with Rheumatoid Arthritis

\section{TABLE 1 Study Population Baseline Characteristics ( $N=2,714$ )}

\begin{tabular}{|c|c|c|c|c|c|}
\hline Demographic Characteristics & $\mathrm{n}$ & $\% \mathrm{a}$ & Medication Use and Clinical Characteristics & $\mathrm{n}$ & $\%^{a}$ \\
\hline \multicolumn{3}{|l|}{ Age groups } & \multicolumn{3}{|l|}{ Adherence to nonbiologic DMARDs } \\
\hline $18-34$ & 334 & 12.3 & Yes $(\mathrm{PDC} \geq 70 \%)$ & 275 & 10.1 \\
\hline $35-44$ & 512 & 18.9 & No $(\mathrm{PDC}<70 \%)$ & 2,439 & 89.9 \\
\hline $45-54$ & 939 & 34.6 & Total & 2,714 & 100.0 \\
\hline $55-63$ & 929 & 34.2 & Mean $( \pm$ SD) & \multicolumn{2}{|c|}{$30.6( \pm 25.2)$} \\
\hline Total & 2,714 & 100.0 & \multicolumn{3}{|l|}{ Persistence with nonbiologic DMARDs (days) } \\
\hline Mean $( \pm$ SD) & \multicolumn{2}{|c|}{$48.1( \pm 10.4)$} & Mean $( \pm S D)$ & \multicolumn{2}{|c|}{$190.2( \pm 201.4)$} \\
\hline \multicolumn{3}{|l|}{ Race/ethnicity ${ }^{b}$} & \multicolumn{3}{|l|}{ Pre-index glucocorticoid utilization ${ }^{c}$} \\
\hline Caucasians & 630 & 23.2 & Yes & 821 & 30.3 \\
\hline African Americans & 286 & 10.5 & No & 1,893 & 69.8 \\
\hline Hispanics & 1,500 & 55.3 & Total & 2,714 & 100.1 \\
\hline Others & 298 & 11.0 & \multicolumn{3}{|l|}{ Post-index glucocorticoid utilizationc } \\
\hline Total & 2,714 & 100.0 & Yes & 1,760 & 64.9 \\
\hline \multicolumn{3}{|l|}{ Gender } & No & 954 & 35.2 \\
\hline Females & 2,418 & 89.1 & Total & 2,714 & 100.1 \\
\hline Males & 296 & 10.9 & \multicolumn{3}{|l|}{ Post-index pain medication utilization ${ }^{\mathrm{d}}$} \\
\hline Total & 2,714 & 100.0 & Yes & 2,507 & 92.4 \\
\hline Medication Use and Clinical Characteristics & $\mathbf{n}$ & $\%{ }^{a}$ & No & 207 & 7.6 \\
\hline \multicolumn{3}{|l|}{ Nonbiologic DMARD type (index drug) } & Total & 2,714 & 100.0 \\
\hline MTX & 1,216 & 44.8 & \multicolumn{3}{|l|}{ Charlson Comorbidity Index score } \\
\hline SSZ & 360 & 13.3 & 2 & $\begin{array}{r}1,399 \\
783\end{array}$ & $\frac{58.9}{28.9}$ \\
\hline HCQ & 682 & 25.1 & $\geq 3$ & 332 & 12.2 \\
\hline LEF & 86 & 3.2 & Total & 2,714 & 100.0 \\
\hline Dual therapy (MTX+SSZ, MTX+HCQ, MTX+LEF) & 370 & 13.6 & Mean $( \pm$ SD) & \multicolumn{2}{|c|}{$1.6( \pm 0.93)$} \\
\hline Total & 2,714 & 100.0 & \multicolumn{3}{|l|}{ Rheumatologist visit } \\
\hline \multicolumn{3}{|l|}{ Nonbiologic DMARD therapy } & Yes & 605 & 22.3 \\
\hline Monotherapy & 2,344 & 86.4 & No & 2,005 & 73.9 \\
\hline Dual therapy & 370 & 13.6 & Missing & 104 & 3.8 \\
\hline Total & 2,714 & 100.0 & Total & 2,714 & 100.0 \\
\hline \multicolumn{6}{|c|}{$\begin{array}{l}\text { aTotals may not equal } 100.0 \text { due to rounding. } \\
\text { bOthers include American Indian, Asian, and unknown. } \\
\text { cGlucocorticoids include oral and injectables. } \\
\text { dPain medications include nonsteroidal anti-inflammatory drugs and opioid analgesics. } \\
\text { DMARD = disease-modifying antirheumatic drugs; HCQ=hydroxychloroquine; LEF=leflunomide; MTX=methotrexate; PDC=proportion of days covered; SD=standard } \\
\text { deviation; SSZ= sulfasalazine. }\end{array}$} \\
\hline
\end{tabular}

significant differences in race/ethnicity, most notably with Caucasians and "other" race categories $(P=0.049)$. When compared with biologic DMARD nonstarters, a higher proportion of biologic DMARD starters had claims for GCs during the pre-index period $(28.2 \%$ vs. $36.3 \%, P<0.0001)$. Similar results were shown in the post-index period (60.1\% vs. $78.7 \%$, $P<0.0001$ ). Although starter and nonstarter groups had low comorbidities (median $\mathrm{CCI}=1$ ), biologic DMARD starters had higher mean CCI scores than biologic DMARD nonstarters (1.73 [ \pm 0.99$]$ vs. $1.56[ \pm 0.90], P<0.0001)$. Regarding prescriber type, a larger proportion of biologic DMARD starters had a rheumatologist visit compared with biologic DMARD nonstarters $(26.6 \%$ vs. 24.1\%, $P=0.002)$. With respect to nonbiologic DMARD type, there were significant $(P<0.0001)$ differences among the individual medications. Most notably, compared with DMARD nonstarters, DMARD starters had a higher proportion of patients on MTX (38.2\% vs. 64.0\%) and a lower proportion on SSZ (15.4\% vs. 7.1\%) and HCQ (30.2\% vs. $10.5 \%)$. No differences were found regarding mono vs. dual therapy. Mean nonbiologic DMARD adherence $32.7 \%$ [ $\pm 25.8 \%]$ vs. $17.2 \%[ \pm 14.7 \%]$ ) and persistence (mean: 225.7 [ \pm 220.1$]$ vs. 178 [ \pm 193.1$]$ days; median: 140.0 vs. 100.0 days) were higher among starters than nonstarters.

\section{Likelihood of Initiation of Biologic DMARDs}

Logistic regression showed that compared with MTX users, SSZ and HCQ users were less likely to initiate biologic DMARDs by $69.0 \%$ (odds ratio $[\mathrm{OR}]=0.310$, 95\% confidence interval $[\mathrm{CI}]=0.221-0.434, P<0.0001)$ and $79.9 \%(\mathrm{OR}=0.201$, $95 \% \mathrm{CI}=0.152-0.265, P<0.0001$ ), respectively (Table 3 ). Dual therapy users were $39.1 \%$ less likely to initiate biologic 


\begin{tabular}{|c|c|c|c|}
\hline \multirow[b]{3}{*}{ Age mean (+ SD)a } & $\begin{array}{l}\text { on of Baseli } \\
\text { istics by Bic } \\
\text { nitiation Sta }\end{array}$ & $\begin{array}{l}\text { ine } \\
\text { ologic } \\
\text { atus }\end{array}$ & \multirow{3}{*}{$\frac{P \text { Value }}{0.03}$} \\
\hline & $\begin{array}{l}\text { Biologic } \\
\text { DMARD } \\
\text { Starters } \\
(n=695)\end{array}$ & $\begin{array}{c}\text { Biologic } \\
\text { DMARD } \\
\text { Nonstarters } \\
(\mathbf{n}=2,019)\end{array}$ & \\
\hline & $47.3( \pm 10.8)$ & $48.3( \pm 10.3)$ & \\
\hline Females, n (\%) & $622 \quad(89.5)$ & $\begin{array}{ll}1,796 & (89.0) \\
\end{array}$ & 0.69 \\
\hline \multicolumn{3}{|l|}{ Race/ethnicity, n (\%) ${ }^{b}$} & $<0.05$ \\
\hline Caucasians & $183 \quad(26.3)$ & $447 \quad(22.1)$ & \\
\hline African Americans & $75 \quad(10.8)$ & $211 \quad(10.5)$ & \\
\hline Hispanics & $375 \quad(54.0)$ & $1,125 \quad(55.7)$ & \\
\hline Others & $62 \quad(8.9)$ & $236 \quad(11.7)$ & \\
\hline $\begin{array}{l}\text { Pre-index glucocorticoid } \\
\text { utilization, } n(\%)^{b}\end{array}$ & $252 \quad(36.3)$ & $569 \quad(28.2)$ & $<0.05$ \\
\hline $\begin{array}{l}\text { Post-index glucocorticoid } \\
\text { utilization, } \mathrm{n}(\%)^{\mathrm{b}}\end{array}$ & $547 \quad(78.7)$ & $1,213 \quad(60.1)$ & $<0.05$ \\
\hline $\begin{array}{l}\text { Post-index pain medication } \\
\text { utilization, } \mathrm{n}(\%)^{\mathrm{b}}\end{array}$ & $644 \quad(92.7)$ & $1,863 \quad(92.3)$ & 0.74 \\
\hline \multicolumn{3}{|l|}{ Charlson Comorbidity Index ${ }^{c}$} & $<0.05$ \\
\hline Median & 1.0 & 1.0 & \\
\hline Mean $( \pm S D)$ & $1.73( \pm 0.99)$ & $1.56( \pm 0.90)$ & \\
\hline \multicolumn{3}{|l|}{ Rheumatologist visit, $\mathrm{n}(\%)^{\mathrm{b}}$} & $<0.05$ \\
\hline Yes & $185 \quad(26.6)$ & $(24.1)$ & \\
\hline No & $420 \quad(60.4)$ & $1,519 \quad(75.2)$ & \\
\hline Missing & $90 \quad(12.9)$ & $14 \quad(0.7)$ & \\
\hline \multicolumn{3}{|c|}{ Nonbiologic DMARD type, $\mathrm{n}(\%)^{\mathrm{b}}$} & $<0.05$ \\
\hline MTX & $445 \quad(64.0)$ & $771 \quad(38.2)$ & \\
\hline SSZ & $(7.1)$ & $311 \quad(15.4)$ & \\
\hline HCQ & $\begin{array}{ll}73 & (10.5) \\
\end{array}$ & $609 \quad(30.2)$ & \\
\hline LEF & $30 \quad(4.3)$ & $56 \quad(2.8)$ & \\
\hline Dual therapy & $(14.1)$ & $(13.5)$ & \\
\hline \multicolumn{3}{|c|}{ Nonbiologic DMARD therapy, $\mathrm{n}(\%)^{\mathrm{b}}$} & 0.68 \\
\hline Monotherapy & $597 \quad(85.9)$ & $\begin{array}{|ll|}1,747 \quad(86.5) \\
\end{array}$ & \\
\hline Dual therapy & $98 \quad(14.1)$ & $272 \quad(13.5)$ & \\
\hline \multicolumn{3}{|c|}{ Adherence (PDC) to nonbiologic DMARD ${ }^{a}$} & $<0.05$ \\
\hline Median & 24.7 & 12.5 & \\
\hline Mean $( \pm S D)$ & $32.7( \pm 25.8)$ & $17.2 \quad( \pm 14.7)$ & \\
\hline \multicolumn{3}{|c|}{ Persistence to nonbiologic DMARD ${ }^{a}$} & $<0.05$ \\
\hline Median & 140.0 & 100.0 & \\
\hline Mean $( \pm S D)$ & $225.7( \pm 220.1)$ & $178.0( \pm 193.1)$ & \\
\hline \multicolumn{4}{|c|}{$\begin{array}{l}\text { aT-test. } \\
{ }^{b} \text { Chi-square test. } \\
{ }^{c} \text { Mann-Whitney U-test. } \\
\text { DMARD=disease-modifying antirheumatic drug; HCQ = hydroxychloroquine; } \\
\text { LEF=leflunomide; MTX = methotrexate; } P D C=\text { proportion of days covered; } \\
\text { SD= standard deviation; SSZ = sulfasalazine. }\end{array}$} \\
\hline
\end{tabular}

DMARDs compared with monotherapy users $(\mathrm{OR}=0.609$, $95 \% \mathrm{CI}=0.463-0.803, P=0.0004)$. With each year increase in age, patients were $1.6 \%$ less likely to start biologic DMARDs (OR=0.984, 95\% CI=0.975-0.993, $\mathrm{P}=0.0006) . \mathrm{GC}$ nonusers were $53.8 \%$ less likely to start on biologic DMARDs than GC users $(\mathrm{OR}=0.462,95 \% \mathrm{CI}=0.372-0.573, P<0.0001)$. Patients with CCI scores of $\geq 3$ were approximately 1.6 times more likely to initiate biologic DMARDs than those with CCI scores of 1 ( $\mathrm{OR}=1.618,95 \% \mathrm{CI}=1.228-2.132, P=0.0006)$. Nonbiologic DMARD type (LEF), gender, race, CCI (score of 2), adherence to nonbiologic DMARDs, pain medication use, and rheumatologist visit were not significantly related to the likelihood of patients initiating biologic DMARDs.

\section{Discussion}

This study examined the factors associated with initiation of biologic DMARDs among RA patients on nonbiologic DMARD therapy using Texas Medicaid prescription and medical claims databases. Results showed that younger age, CCI scores $\geq 3$, GC use, MTX use, and nonbiologic DMARD monotherapy use were significantly associated with a higher likelihood to initiate biologic DMARDs. This study is among the first to use large health claims databases to assess the driving factors in the transition from nonbiologic DMARD to biologic DMARD use among RA patients.

The associations between younger age and GC use and higher likelihood of initiating biologic DMARDs was consistent with findings from Dewitt et al. (2009). ${ }^{18}$ As older patients are more susceptible to the immunosuppressant side effects of biologic DMARDs, younger patients are relatively more likely to be prescribed and initiate biologic DMARDs. The positive association between GC use and biologic DMARD initiation suggests that biologic initiators experience higher RA severity, thus, using GC prior to the initiation of biologic DMARDs.

MTX users were more likely to initiate biologic DMARDs compared with SSZ and HCQ users. MTX users had relatively higher adherence and persistence compared with other nonbiologic DMARDs (results not shown); this may signify that the MTX user group may have had more severe RA and thus were motivated to adhere and seek additional treatment.

Unexpectedly, nonbiologic DMARD dual therapy users were less likely to start on biologic DMARDs when compared with monotherapy users. This relationship requires further investigation, but it may be likely that the use of 2 therapies was effective enough to delay biologic DMARD initiation. In addition, this may suggest that patients more frequently transition from nonbiologic DMARD monotherapy to biologic DMARDs than from nonbiologic DMARD dual therapy to biologic DMARDs, which is inconsistent with current treatment guidelines. Based on this observation, and in accordance with guidelines, providers may want to consider nonbiologic DMARD combination therapy use before moving on to biologic DMARDs.

While the current study revealed that higher CCI scores $(\mathrm{CCI} \geq 3)$ were associated with higher likelihood of starting biologic DMARDs, Dewitt et al. did not find any significant association with comorbidity, which was defined differently as reported comorbidities. ${ }^{18}$ The association between high CCI scores and initiation of biologic DMARDs may imply that patients with comorbid conditions seek more aggressive treatment, since they experience higher pain or have a different treatment approach 
Factors Associated with the Initiation of Biologic Disease-Modifying Antirheumatic Drugs in Texas Medicaid Patients with Rheumatoid Arthritis

TABLE 3 Logistic Regression of Initiation of Biologic DMARDs by Nonbiologic DMARD Type $(\mathrm{N}=2,714)$

\begin{tabular}{|c|c|c|c|c|}
\hline & Odds Ratio & $95 \%$ CI & Wald $X^{2}$ & $P$ Value \\
\hline \multicolumn{5}{|l|}{ Nonbiologic DMARD type } \\
\hline SSZ & 0.310 & $0.221-0.434$ & 46.3 & $<0.05$ \\
\hline HCQ & 0.201 & $0.152-0.265$ & 128.4 & $<0.05$ \\
\hline LEF & 0.817 & $0.509-1.312$ & 0.7 & 0.40 \\
\hline \multicolumn{5}{|l|}{ Nonbiologic DMARD therapy } \\
\hline Dual therapy & 0.609 & $0.463-0.803$ & 12.4 & $<0.05$ \\
\hline \multicolumn{5}{|l|}{ Covariates } \\
\hline Age & 0.984 & $0.975-0.993$ & 11.9 & $<0.05$ \\
\hline Female & 1.008 & $0.738-1.376$ & 0.0023 & 0.96 \\
\hline \multicolumn{5}{|l|}{ Race/ethnicity } \\
\hline African Americans & 0.879 & $0.625-1.237$ & 0.55 & 0.46 \\
\hline Hispanics & 0.951 & $0.755-1.196$ & 0.19 & 0.67 \\
\hline Others & 0.646 & $0.455-0.918$ & 5.94 & 0.02 \\
\hline Glucocorticoid nonuser post-index & 0.462 & $0.372-0.573$ & 48.99 & $<0.05$ \\
\hline Pain medication nonuser post-index & 1.105 & $0.742-1.645$ & 0.24 & 0.62 \\
\hline \multicolumn{5}{|l|}{ Charlson comorbidity at index } \\
\hline 2 & 1.223 & $0.987-1.517$ & 3.38 & 0.07 \\
\hline$\geq 3$ & 1.618 & $1.228-2.132$ & 11.70 & $<0.05$ \\
\hline Nonadherent to nonbiologic DMARDs (PDC $<70 \%)$ & 0.936 & $0.632-1.388$ & 0.11 & 0.74 \\
\hline Persistence to nonbiologic DMARDs & 1.001 & $1.000-1.001$ & 4.50 & 0.03 \\
\hline Rheumatologist visit & 1.174 & $0.946-1.459$ & 2.12 & 0.15 \\
\hline
\end{tabular}

Note: Reference groups = MTX, monotherapy, male, Caucasians, glucocorticoid user, pain medication user, Charlson Comorbidity Index score=1, adherent to nonbiologic DMARD, and nonrheumatologist visit.

$C I=$ confidence interval; $D M A R D=$ disease-modifying antirheumatic drug; $H C Q=$ hydroxychloroquine; $L E F=$ leflunomide; $M T X=$ methotrexate; $P D C=$ proportion of days covered; SSZ = sulfasalazine.

from those without comorbid conditions. Given these results, providers may want to consider screening RA patients for comorbid conditions, as well as providing a thorough RA therapy evaluation to ensure optimal RA management.

Based on our findings, patients who are more likely to initiate biologic DMARDs should be targeted to re-evaluate appropriateness of RA therapy. For future studies, it would be worthwhile to include clinical factors as well as patients' attitudes and behaviors toward RA therapy in examining the association with initiating biologic DMARDs.

\section{Limitations}

This study utilized PDC as a proxy for measuring medication adherence; however, patients may not have taken their medications at all or as directed. Dual therapy was defined as having 2 nonbiologic DMARDs filled with 2 overlapping periods of at least 15 days, with the first claim filled within 4 months of the index date. This definition was stringent, and it may have misclassified monotherapy users who might have actually been dual therapy users. Using the retrospective claims database precluded access to other relevant clinical information (e.g., RA disease activity level and pain assessment). Including such clinical variables would make the analyses more robust because RA severity could be controlled. Finally, the study findings are only generalizable to the Texas Medicaid population.

\section{Conclusions}

In this retrospective health claims database study, younger age, CCI scores $\geq 3$, GC use, MTX use (vs. SSZ and HCQ use), and nonbiologic DMARD monotherapy use (vs. dual therapy use) were significantly associated with higher likelihood to initiate biologic DMARDs. Health care providers and Texas Medicaid should recognize these potential factors associated with the initiation of biologic DMARDs and make efforts to achieve optimal therapy for RA patients through thorough RA medication evaluation, well-structured RA monitoring programs, and patient education.

\section{Authors}

GILWAN KIM, PharmD, MS, is Graduate Student; JAMIE C. BARNER, PhD, is Professor; and KAREN RASCATI, PhD, is Professor, Health Outcomes and Practice, College of Pharmacy, The University of Texas at Austin. KRISTIN RICHARDS, PhD, is Research Associate, Center for Pharmacoeconomic Studies, College of Pharmacy, The University of Texas at Austin.

AUTHOR CORRESPONDENCE: Jamie C. Barner, PhD, College of Pharmarcy, The University of Texas, 2409 University Ave., STOP A1930, Austin, TX 78712-1120. Tel.: 512.471.5612;

E-mail: jbarner@austin.utexas.edu. 


\section{DISCLOSURES}

No financial support was provided for this research. The authors declare no conflicts of interest.

Study concept and design was contributed primarily by Kim and Barner, with help from Rascati and Richards. Data collection was performed primarily by Kim, along with Barner, and analysis was carried out by all authors equally. The manuscript was written by Kim and Barner and revised by Kim, Barner, and Richards.

\section{REFERENCES}

1. Scott DL, Wolfe F, Huizinga TW. Rheumatoid arthritis. Lancet. 2010;376 (9746):1094-108

2. Centers for Disease Control and Prevention. Rheumatoid arthritis. 2012. Available at: http://www.cdc.gov/arthritis/basics/rheumatoid.htm. Accessed March 25, 2015.

3. Filipovic I, Walker D, Forster F, Curry AS. Quantifying the economic burden of productivity loss in rheumatoid arthritis. Rheumatology (Oxford). 2011;50(6):1083-90

4. O'Dell J. Rheumatoid arthritis. In: Goldman L, Schafer A, eds. Goldman's Cecil Medicine. 24th ed. Philadelphia: Saunders Elsevier; 2011:1681-89.

5. Wells B. Rheumatoid arthritis. In: Wells B, Dipiro J, Schwinghammer T, Dipiro C, eds. Pharmacotherapy Handbook. 7th ed. New York: McGraw-Hill; 2009:35-37.

6. Helmick CG, Felson DT, Lawrence RC, et al. Estimates of the prevalence of arthritis and other rheumatic conditions in the United States. Part I. Arthritis Rheum. 2008;58(1):15-25. Available at: http://onlinelibrary.wiley. com/doi/10.1002/art.23177/pdf. Accessed March 25, 2015.

7. Lawrence RC, Felson DT, Helmick CG, et al. Estimates of the prevalence of arthritis and other rheumatic conditions in the United States. Part II. Arthritis Rheum. 2008;58(1):26-35. Available at: http://www.ncbi.nlm.nih.gov/pmc/ articles/PMC3266664/pdf/nihms347693.pdf. Accessed March 25, 2015.

8. Woolf AD, Pfleger B. Burden of major musculoskeletal conditions. Bull World Health Organ. 2003;81(9):646-56. Available at: http://www.ncbi.nlm.nih. gov/pmc/articles/PMC2572542/pdf/14710506.pdf. Accessed March 25, 2015.
9. Cho SK, Kim D, Jun JB, Bae SC, Sung YK. Factors influencing quality of life (QOL) for Korean patients with rheumatoid arthritis (RA). Rheumatol Int. 2013:33(1):93-102.

10. Michaud K, Wolfe F. Comorbidities in rheumatoid arthritis. Best Pract Res Clin Rheumatol. 2007;21(5):885-906.

11. Sokka T, Abelson B, Pincus T. Mortality in rheumatoid arthritis: 2008 update. Clin Exp Rheumatol. 2008;26(5 Suppl 51):S35-61.

12. Kleinman NL, Cifaldi MA, Smeeding JE, Shaw JW, Brook RA. Annual incremental health benefit costs and absenteeism among employees with and without rheumatoid arthritis. J Occup Environ Med. 2013;55(3):240-44.

13. Singh JA, Furst DE, Bharat A, et al. 2012 update of the 2008 American College of Rheumatology recommendations for the use of disease-modifying antirheumatic drugs and biologic agents in the treatment of rheumatoid arthritis. Arthritis Care Res (Hoboken). 2012;64(5):625-39. Available at: http:// www.ncbi.nlm.nih.gov/pmc/articles/PMC4081542/pdf/nihms586934.pdf. Accessed March 25, 2015.

14. Smolen JS, Landewe R, Breedveld FC, et al. EULAR recommendations for the management of rheumatoid arthritis with synthetic and biological disease-modifying antirheumatic drugs: 2013 update. Ann Rheum Dis. 2014;73(3):492-509. Available at: http://www.ncbi.nlm.nih.gov/pmc/articles/ PMC3933074/pdf/annrheumdis-2013-204573.pdf. Accessed March 25, 2015

15. Keystone EC, Smolen J, van Riel P. Developing an effective treatment algorithm for rheumatoid arthritis. Rheumatology (Oxford). 2012;51(Suppl 5): v48-54. Available at: http://rheumatology.oxfordjournals.org/content/51/ suppl_5/v48.full.pdf+html. Accessed March 25, 2015.

16. Smolen JS, Aletaha D, Koeller M, Weisman MH, Emery P. New therapies for treatment of rheumatoid arthritis. Lancet. 2007;370(9602):1861-74.

17. Thomson Healthcare. Micromedex. August 2013. Greenwood Village, CO. Available at: http://www.micromedexsolutions.com. Accessed April 8, 2015.

18. Dewitt EM, Lin L, Glick HA, Anstrom KJ, Schulman KA, Reed SD. Pattern and predictors of the initiation of biologic agents for the treatment of rheumatoid arthritis in the United States: an analysis using a large observational data bank. Clin Ther. 2009;31(8):1871-80. Available at: http:// www.ncbi.nlm.nih.gov/pmc/articles/PMC3518838/pdf/nihms396556.pdf. Accessed March 25, 2015. 